\title{
The Teaching Present Situation of Economic Mathematics and the Countermeasures
}

\author{
Wang Hong \\ College of Finance, \\ Shandong Institute of Light Industry \\ Jinan, China \\ e-mail: jmjj55@126.com
}

\author{
Zhao Peiyi \\ Education , Recruitment and Examination , \\ Shandong Provincial Academy \\ Jinan, China \\ e-mail: pyzhao@126.com
}

\begin{abstract}
As a basic study of most economic colleges, Economic Mathematics has permeated through various fields, In view of the problems in Economic Mathematics teaching, relevant countermeasures against problems are given here, such as infiltrating the human spirit, focusing on application perspective, introducing economic models, integrating the mathematical experiments. These will bring about the reform in teaching system and teaching content.
\end{abstract}

Keywords- Economic Mathematics; humanistic spirit; economic models ; mathematical experiments

\section{INTRODUCTION}

With the globalization of economic development, the fast development of computer and the diversification of economic problems, mathematics has become the mainstay of the economy and management. A large number of economic problems should be analyzed by applied mathematics, such as Financial Mathematics, Actuarial Science, Mathematical Economics and Econometrics. As a basic study of most economic colleges, Economic Mathematics is pretty important to establishing a system of specialized knowledge for the economy-related majors. However, mathematical application on the economy and management is usually ignored in teaching. The students cannot realize the importance and value of Economic Mathematics. This paper will give some specific measures which are based on the present situation of Economic Mathematics teaching.

\section{PRESENT Situation OF ECONOMIC Mathematics TEACHING}

\section{A. Too much Emphasis on Theory Teaching Lowers Students' Interest in Learning}

In the process of learning Economic Mathematics, students hardly have a deep understanding because of the abstract conception. Instructors still use the force-feeding method of teaching during the teaching process, and they excessively emphasize the proof of concepts and theorems, which will lead to the students' lack of enthusiasm and interest in learning. Finally the students lose the interest and the selfinnovation ability in passive study, and this affects the achievement of teaching target ${ }^{[1]}$.

\section{B. Separation Between Theory and Specialized Courses, Lack of Cultivation of Mathematics Application Sense}

Firstly, the traditional mathematics teaching does not reflect the unique character of Economic Mathematics, and many mathematical methods which are useful for economic research are not reflected in Economic Mathematics teaching. There is no mutual penetration between economy and mathematics, so the students learn many mathematical theorems and formulas, and very few economic concepts are referred to. Therefore, the students can not apply Economic Mathematical method to analyze economic problems, and they will feel that it is of no use to learn Economic Mathematics.

Secondly, application awareness is the key to use mathematical ideas and methods to solve problems. No application awareness, no behavior. In many financial colleges, professional mathematics mindset and theoretical knowledge for Mathematics majors are introduced in Economic Mathematics teaching. The in-depth studies to the mathematical theory do not enable students to learn more about the background and development of mathematical concepts, and the contact between mathematics and other subjects. All of these lead to the students' lack of mathematics application awareness ${ }^{[2]}$.

\section{Old Teaching Mode cannot Meet the Needs of the Development of the Times}

With the rapid development of the socioeconomic and Internet technology, traditional classroom teaching can not satisfy the needs of the development of the Times. The traditional classroom teaching, which focuses on the teaching materials, classrooms and teachers, can not keep the pace with the development needs of the times. The teaching methods, which are obsolete and lacking in vivid content, make the students unable to mobilize the enthusiasm. Therefore, the effect of Economic Mathematics teaching is not ideal. 


\section{COUNTERMEASURES IN THE ECONOMIC MATHEMATICS TEACHING}

\section{A. Infiltrate Humanistic Spirit and Cultivate the Students' Interest in Learning}

In college education, the humanistic spirit behind Economic Mathematics teaching should be taken seriously. Based on the real situation of students, the humanistic spirit must be infiltrated when we attach importance to scientificness, which is useful to the cultivation of students' cultural quality and the improvement of their mathematical interest.

Firstly, besides imparting the basic knowledge and basic skills to the students, teachers should explore the beauty of mathematics, guide students to discover and appreciate the beauty of mathematics, stimulate students' curiosity and cultivate their creative thinking ability. Secondly, the history of mathematics is a history of innovation. The story of many mathematicians in their growth and study will greatly stimulate students to have a strong interest in mathematics. The function of the humanistic spirit is enormous ${ }^{[3]}$. Thirdly, harmonious atmosphere of classroom teaching can help the students' form a positive attitude. The teachers' humorous and vivid words could activate the minds of students. In the teaching process, new flexible teaching methods should be introduced, such as using problems as an analogy to the phenomenon in real life, and introducing the mathematical story. The students could have interest in learning and obtain the mathematical knowledge in a harmonious and relaxed classroom atmosphere.

\section{B. Focus on Application Perspective, Introduce Economic Models}

\section{(1) The Hidden Role of Mathematics}

In the information era, for example, we need to use the geometric projection in precision farming when we convert satellite positioning map into a flat soil map; it involves methods of measurement, image analysis, and statistical quality control in the fabrication process of the semiconductor; commercial aircrafts are required to achieve the optimization of the system as a whole like design, manufacture, maintenance, and management. These examples are different from the traditional application of the mathematical theory; they are "Math practice". So teachers should make students feel the important application value of learning Economic Mathematics from the hidden function of mathematics.

\section{(2) Introduce Economic Models}

Mathematical concepts and knowledge are abstracted away from the real world ${ }^{[4]}$. While teaching, teachers should pay attention to the use of higher mathematical theory in economic field with more examples, introduce economic mathematics concept into the classic case of economic management, and this make students feel the usefulness of mathematics. When imparting mathematical knowledge, teachers should link the economic phenomenon and economic problems, such as savings, interest rate, stock, bond, tax revenue, risk prediction and control, optimization, and mathematical statistics and so on, which should be incorporated into the teaching content. So it is necessary to build a bridge between theory and application.

Selecting the appropriate models according to the different major characteristics and illustrating mathematical concepts using the economic models, is one teaching way to push some students to work harder. For example, as an important concept, Derivative is used in economic analysis widely. We can introduce the importance and extensive application of comparative statics when the concept of multiple-variable calculus, total differential and the derivative of implicit function is given. For example, the simple model "partial equilibrium market":

$$
\mathrm{Q}_{d}=Q_{s}, \mathrm{Q}_{d}=a-b p(a, b>0), Q_{s}=-c+d p(c, d>0)
$$

$P^{*}, Q^{*}$ means the initial equilibrium. Students may feel that Derivative is very important to the comparative statics analysis by learning this model. We can get the following formula by taking the partial derivatives:

$$
P^{*}=\frac{a+c}{b+d}, \quad Q^{*}=\frac{a d-b c}{b+d}
$$

and know how the infinitesimal change of a parameter affects the value of the equilibrium value. This can help students to apply partial differential to develop economical solutions ${ }^{[5]}$.

\section{(3) Apply Modern Educational Technology, and Integrate Mathematical Experiments into Teaching}

The rapid development and wide application of information technology provide favorable conditions for the development of modern educational technology.

Computer-aided instruction can provide lots of information to students in limited time, and its artistry and relish stimulate students' interest and desire for knowledge. But considering economic mathematics characteristics, it is fairly more distinct to use the blackboard to teach the computational process of the determinant of the linear algebra and the linear equations. Therefore, it is necessary to combine the traditional classroom teaching and the multimedia teaching to optimize the teaching procedures ${ }^{[6]}$.

Meanwhile, the application of mathematical softwares plays an extremely important role in teaching process. Complex calculations can be done using mathematical softwares, such as MATLAB, Mathematic and so on. These softwares can solved many problems, such as limit operation, derived operation, integral operation, graph drawing, numeric algorithm, the solutions of linear equations and so on. These softwares help students to understand the fundamental mathematical concept and simplify the mathematical calculations. 


\section{(4) Pay Attention to Academic Competition}

Academic competition, as an important way of cultivating high-quality talents ${ }^{[7]}$, focuses on the problemsolving ability of students. The results of the competitions reflect the students' ability to understand and solve problems, and their mental and physical condition. Organizing college students to participate in academic competitions, such as Mathematical Modeling Competition and National Mathematics Contest for College Students, could arouse the students' interests and enhance their problem-solving skills.

\section{CONCLUSION}

Economic Mathematics teaching is an important and complicated issue. The students' interests could be aroused by infiltrating humanistic spirit in teaching. The introduction of economic models and modern technology greatly expands the teaching and independent learning space, further stimulates the students' learning initiative and enthusiasm and cultivates the students' innovative ability. The effective combination of theory teaching and practice teaching reflects the application features of Economic Mathematics and the role as a tool.All of these would cultivate the students' application competence and help them use Economic Mathematics knowledge to participate in economic process, which would help train excellent application talents for society in the economy field.

\section{REFERENCE}

[1] Yan Shijian, "Yan Shijian talk about mathematics, education," Dalian: Dalian University of Technology Press, pp. 105-106, 2010

[2] Hu Hong, "Talk a few of College mathematics teaching," Huaiyin Normal Univercity Educational Science forum, 2006

[3] Liang Yan, "Talk a few of the humanities spirit in College mathematics teaching,”, Shijiazhuang Institute of Technology academic study, Vol.6, No.2, 2011

[4] He Peiling, "The teaching of economic mathematics focus on application angle,” Contemporary educational theory and practice, Vol.3, No.1, 2011

[5] Wang Xiaoshuo, “ The discussion of introducing economic models in economic mathematic teaching," Enterprise technology and development,2010

[6] Shen Haiyan, “Appling modern educational technology, promoting the economic mathematics reform," Journal of Guangdong University of Technology,2010

[7] Chen Yu, "Cultivation of initiative in economic mathematic teaching," Journal of Ganzhou Normal University,2012 